\title{
Monitoring peri-operative immune suppression in renal cancer patients
}

\author{
SABINE HASE ${ }^{1}$, KRISTIN WEINITSCHKE $^{1}$, KIRSTEN FISCHER $^{2}$, PAOLO FORNARA $^{2}$, \\ RASCHID HODA $^{2}$, SUSANNE UNVERZAGT ${ }^{3}$, BARBARA SELIGER ${ }^{1}$ and DAGMAR RIEMANN ${ }^{1}$ \\ ${ }^{1}$ Institute of Medical Immunology, ${ }^{2}$ Clinic of Urology, and ${ }^{3}$ Institute of Medical Epidemiology and Biometry \\ and Medical Informatics, Martin Luther University Halle-Wittenberg, D-06112 Halle, Germany
}

Received November 4, 2010; Accepted December 29, 2010

DOI: 10.3892/or.2011.1199

\begin{abstract}
The aim of this study was the identification of surrogate markers of host immunity in renal cell carcinoma (RCC) patients. Using 4-color flow cytometry the immunophenotype of blood immune cells of RCC patients was compared to that of healthy volunteers and correlated with staging and grading of patients. Furthermore, the time course of these immune markers was compared in RCC patients undergoing either open surgery or laparoscopy. Compared to the healthy control group, blood of RCC patients contained more granulocytes and higher percentages of CTLA $4{ }^{+} \mathrm{CD} 8^{+} \mathrm{T}$ lymphocytes, but reduced numbers of dendritic cells (DCs) and of CD28 $8^{+}$ $\mathrm{CD} 8{ }^{+} \mathrm{T}$ cells. Tumor progression was associated with a higher white blood cell count, a reduced frequency of blood DCs and increased numbers of $\mathrm{CD} 57^{+} \mathrm{T}$ and NK cells. Monocytes of patients with advanced RCC showed a reduced HLA-DR surface expression associated with higher aminopeptidase $\mathrm{N}(\mathrm{APN}) / \mathrm{CD} 13$ expression. Tumor surgery caused an increase of granulocytes and a decrease of all lymphocytic and DC subpopulations within $24 \mathrm{~h}$, whereas the number of HLA-DR low monocytes was up-regulated. As demonstrated by time kinetic analysis, laparoscopic intervention caused a more moderate immunosuppression and an enhanced restoration of immune activity than open surgery. These results suggest that the composition and the phenotype of innate immune cells reflect well the differences in the cellular immunity of RCC patients associated with tumor disease as well as surgery. The monocytic HLA-DR intensity represents a suitable marker for monitoring tumor stage and surgery-associated immunosuppression in RCC patients.
\end{abstract}

Correspondence to: Dr Dagmar Riemann, Institute of Medical Immunology, Martin Luther University Halle-Wittenberg, Magdeburger Strasse 2, D-06112 Halle, Germany

E-mail: dagmar.riemann@medizin.uni-halle.de

Key words: immune monitoring, cytometry, renal cancer, HLA-DR, aminopeptidase N/CD13

\section{Introduction}

Renal cell carcinoma (RCC) is known as an immunosensitive tumor. Surgical management with radical or partial nephrectomy is the most effective treatment for patients with localized disease. In patients with advanced or recurrent metastatic RCC, immune modulation-based therapies, such as low dose IL-2 and IFN- $\alpha$ treatment have been used for more than 20 years to improve cancer-specific survival. However, the efficacy of both substances is rather low. Recently, targeted therapies have increased both objective response rates and disease-free survival of RCC patients, in particular drugs inhibiting the vascular endothelial growth factor (VEGF) and the mammalian target of rapamycin (mTOR) pathway $(1,2)$.

Accurate prediction of long-term disease-free survival immediately after surgical resection of clinically localized and advanced disease would be valuable for patient counseling, scheduling follow-up imaging and identifying poor risk group patients who might benefit from enrollment in adjuvant therapy protocols. However, so far tumor stage, tumor grade, and patient performance status remain the most useful and clinically available predictors of RCC patients' outcome (reviewed in ref. 3). Up to now, there exist only few data on prognosis-relevant markers of the immune system, among them a high number of blood granulocytes, which correlates with poor prognosis (4). In addition, high number of regulatory $\mathrm{T}$ cells (Treg) and of myeloid suppressor cells (MDSC) in patients with advanced RCC could be associated with reduced survival (5-7).

Major surgical trauma promotes an immunologic dysfunction that predisposes patients to significant morbidity. Recent studies suggest that the impairment of the immune system parallels the degree of surgical trauma and tissue injury (8). Deficient immune responses in the early postoperative period may facilitate the implantation of disseminated tumor cells and their early metastatic growth. Advances in laparoscopic approaches and equipment have allowed surgeons to perform technically more complex reconstructive and organ-preserving surgery. Since its introduction in 1990, the implementation of laparoscopic radical nephrectomy is increasing worldwide. In the hands of experienced laparoscopic urological surgeons 
and with adherence to established principles of open radical nephrectomy, laparoscopic radical nephrectomy is now the recommended standard of care for patients with $\mathrm{T} 2$ tumors and smaller renal masses not treatable by nephron-sparing surgery (9). Advantages of laparoscopic techniques are less blood loss, faster recovery time and shorter hospital stay (10). Minimally invasive methods are less stressful and appear to reduce the systemic acute phase reaction associated with open surgery.

In our study the perioperative cellular immune responses were investigated in patients undergoing open and laparoscopic tumor surgery for localized RCC. Using multicolor flow cytometry, we first compared the composition of blood immune cells of RCC patients prior surgery with an agematched control group, correlated the phenotype of patients' immune cells with tumor stages and grades, and performed an one-week time kinetics of the blood immune cell repertoire in both patients groups. Besides the quantification of blood immune cells, we chose markers of cellular activation (such as HLA-DR, CD25, CXCR3 for T cells), cellular senescence and exhaustion (e.g. CD57,CTLA4, PD1), and suppressive function (FoxP3). Furthermore, we quantified the expression of HLA-DR and aminopeptidase N/CD13 on monocytes, molecules known to be involved in antigen presentation.

\section{Materials and methods}

Patient samples. The study comprised 44 RCC patients who underwent surgery of the primary tumor at the Department of Urology of the Martin Luther University Halle-Wittenberg. Twenty-seven patients were operated per laparatomy and 17 patients with laparoscopy. The study was performed with the approval from the Ethics Committee of the University, and all patients gave their informed consent. The average age was 66.05 years (range 43-86 years). Twenty-four patients were male and 20 were female. Histology, tumor grading and staging are given in Table I. EDTA blood $(9 \mathrm{ml})$ was received from RCC patients at least one day before operation as well as on days 1,3 and 7 after surgery, and prepared within 4-6 h. Twenty healthy individuals with a mean age of 59 years (range 40-78 years) without tumor disease in clinical history served as controls.

Antibodies and sample preparation. A lysed whole blood technique with 4-color staining of blood cells was used. The monoclonal antibodies (mAbs) purchased from BD Biosciences (Heidelberg, Germany) were CD3, CD8, CD19, CD25, CD56, CTLA4/CD152, PD1/CD279; those purchased from Beckman Coulter GmbH (Krefeld, Germany) included CD14, CD16, CD28, CD57 and TCRV 224 . The FoxP3 staining buffer set (clone PCH101) of eBioscience (San Diego, CA) was used for staining of $\mathrm{CD}^{+}{ }^{+}$regulatory $\mathrm{T}$ cells. Circulating dendritic cell (DC) populations were identified by using a 'Blood Dendritic Cell Enumeration Kit' according to the manufacturer's instructions (Miltenyi, Bergisch Gladbach, Germany). Briefly, aliquots of whole blood were labeled with a cocktail of mAbs including anti-CD14-PE-Cy5 and anti-CD19-PE-Cy5 plus or minus anti-CD1c-PE as a marker for type-1 myeloid DC (mDC1), CD141/BDCA-3-APC (mDC2) or CD303/BDCA-2-FITC for plasmacytoid DC (pDC). After incubation, red cell lysis and washing, cells were fixed and
Table I. Patient characteristics.

Laparoscopic Laparotomy group $(n=17)$ group $(n=27)$ P-value

\begin{tabular}{|c|c|c|c|}
\hline $\begin{array}{l}\text { Age, median } \\
\text { (range, years) }\end{array}$ & $66(45-86)$ & $67(43-77)$ & 0.966 \\
\hline Gender, n (\%) & & & 0.042 \\
\hline Female & $11(65)$ & $9(33)$ & \\
\hline Male & $6(35)$ & $18(67)$ & \\
\hline pT stage, n (\%) & & & 0.195 \\
\hline pT1a & $6(35)$ & $8(30)$ & \\
\hline pT1b & $7(41)$ & $5(18)$ & \\
\hline pT2 & $2(12)$ & $4(15)$ & \\
\hline pT3a & $1(6)$ & $4(15)$ & \\
\hline pT3b & $1(6)$ & $6(22)$ & \\
\hline Tumor grade, $\mathrm{n}(\%)$ & & & 0.730 \\
\hline G1 & $3(18)$ & $5(18)$ & \\
\hline G2 & $12(70)$ & $16(59)$ & \\
\hline G3 & $2(12)$ & $6(22)$ & \\
\hline Histological type, n (\%) & & & 0.158 \\
\hline Clear cell & $13(76)$ & $25(93)$ & \\
\hline Papillary & $1(6)$ & $2(7)$ & \\
\hline Papillary/clear cell & $1(6)$ & & \\
\hline Chromophobe & $1(6)$ & & \\
\hline Unclassified & $1(6)$ & & \\
\hline Operation technique, n (\%) & & & 0.298 \\
\hline Radical nephrectomy & $15(88)$ & $18(67)$ & \\
\hline Nephron-sparing surgery & $2(12)$ & $9(33)$ & \\
\hline
\end{tabular}

examined using a FACSCalibur and the Cellquest software (BD Biosciences). Results are expressed as percentage of DC in white blood cells (WBC) or as absolute numbers $/ \mu 1$ of blood.

The expression of HLA-DR and aminopeptidase N(APN)/ CD13 on monocytes was evaluated using mAbs labeled on a protein/fluorophore ratio of 1/1 (QuantiBRITE ${ }^{\mathrm{TM}}$ reagents; BD Biosciences). A standard curve for antigen quantification was established using multilevel calibrated QuantiBRITE beads. The fluorescence was measured as specific geometric mean fluorescence intensity (MFI) of the gated population and converted into antibody molecules bound per cell (ABC) using Microsoft Excel ${ }^{\mathrm{TM}}$ spreadsheet. Taking the geometric mean representing 5,000 $\mathrm{ABC}$ as borderline value, we estimated the amount of HLA-DRlow monocytes as percentage of CD14+ cells. The anti-HLA-DR 1/1 PE (clone L243)/ anti-CD14 PerCP-Cy5.5 mAb (BD Biosciences) was used according to the manufacturer's instruction and measured in $1 \mathrm{ml}$ PBS without any washing steps. The CD13 antigen was detected using the $\mathrm{mAb}$ clone Leu-M7, prepared as a customer conjugate (BD Biosciences). Staining for CD13 was done similarly as with HLA-DR, with the exception of two washing steps after lysis of erythrocytes. For the gating of monocytes, a CD14-specific FITC-labeled mAb was additionally included. 

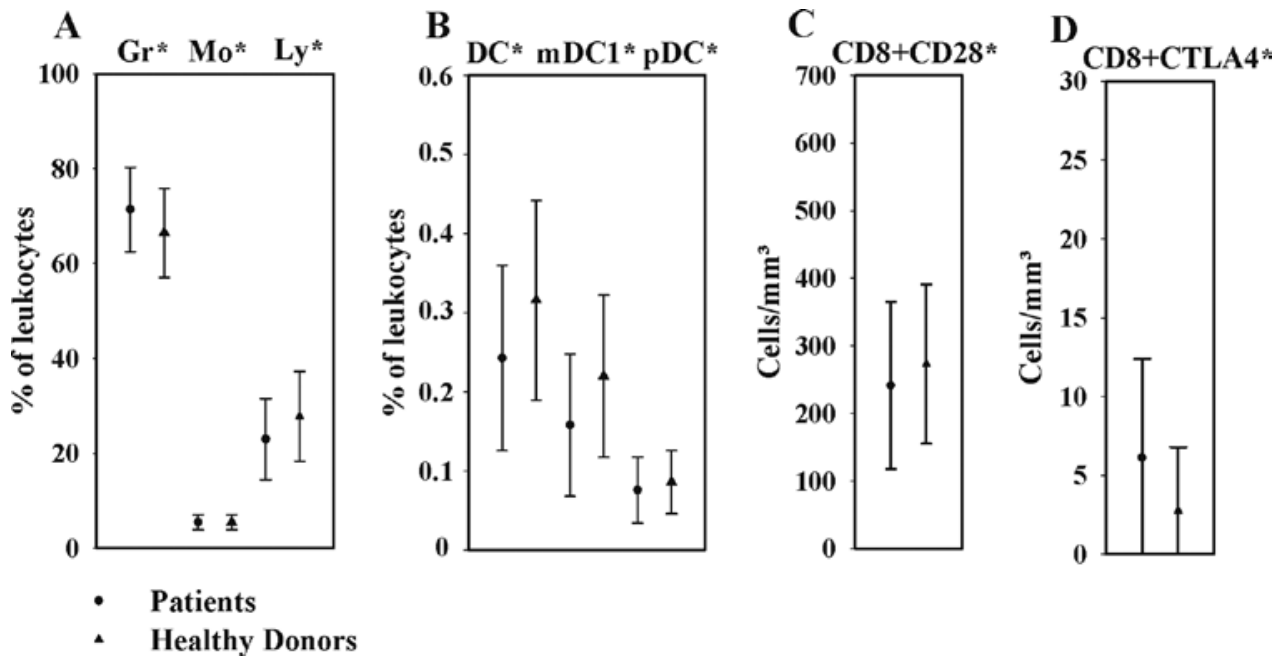

Figure 1. Distribution of immune cells in the blood of RCC patients and healthy volunteers. The leukocyte distribution of granulocytes (Gr), monocytes (Mo) and lymphocytes (Ly) is shown in (A), the number of different subpopulations of DC as \% of leukocytes in (B). The absolute values of CD28 $8^{+}$cytotoxic T cells is given in (C) and of CTLA4+ cytotoxic T cells in (D). Mean values \pm SD are shown, significant differences are marked by an asterisk.
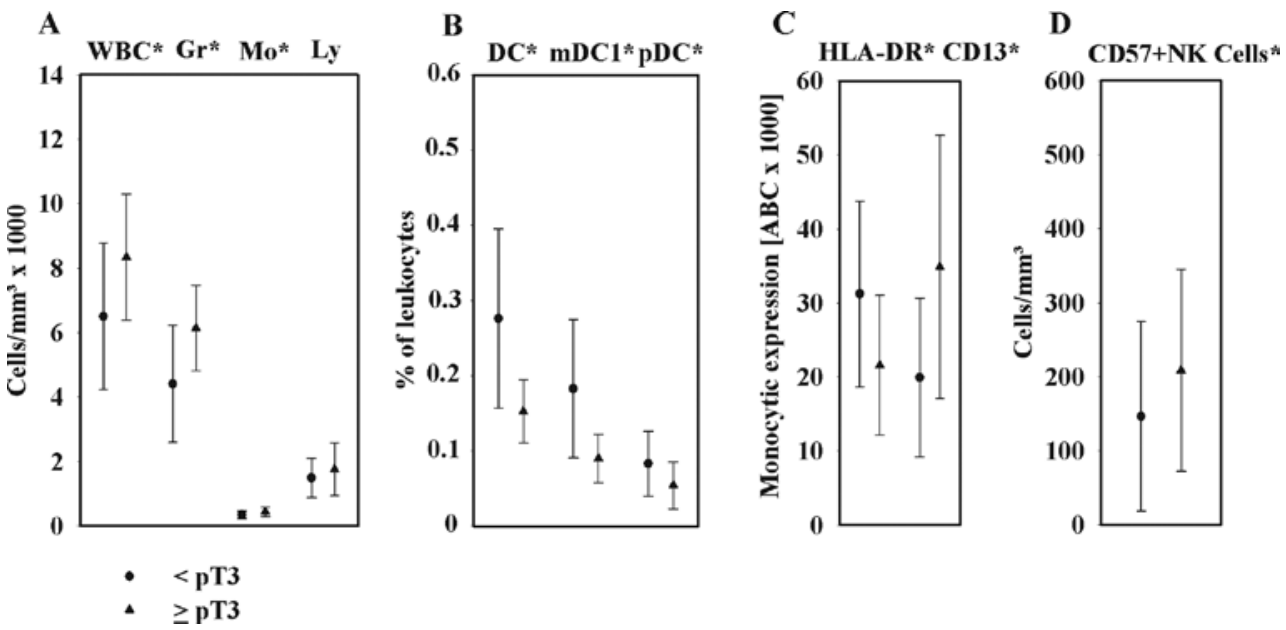

Figure 2. Correlation of the frequency of immune cell populations in the blood of RCC patients with tumor stages $<\mathrm{pT} 3$ and $\geq \mathrm{pT} 3$. The absolute number of WBC, of granulocytes, monocytes and lymphocytes of RCC patients is illustrated in (A), DC (sum of all subtypes, MDC1 and PDC) as the percentage of leukocytes in (B), the monocytic intensity of the surface molecules HLA-DR and APN/CD13 is shown as 'antibodies bound per cell' (ABC) in (C) and the count of $\mathrm{CD} 7^{+} \mathrm{NK}$ cells is given in (D). Mean values \pm SD are shown, significant differences are marked by an asterisk.

Flow cytometric analysis of immune cells was performed using a FACSCalibur ${ }^{\mathrm{TM}}$ (BD Biosciences) with the CellQuest ${ }^{\mathrm{TM}}$ software. Lymphocytes, monocytes and granulocytes were separated on the basis of their forward scatter and side scatter patterns, and the staining for CD14 was used to identify monocytes. At least 5,000 cells in the region of interest were counted.

Statistical analysis. Results are given as the mean \pm SEM. The statistical analysis was done using the commercial software SPSS 17.0 (SPSS Inc., Munich, Germany). Differences in the absolute cell count of immune cells and the relative percentages between patients and healthy volunteers, patients with different tumor stages and grading, and differences at each time point were analysed using Student's t-test, Wilcoxon-Mann-Whitney test, Kruskal-Wallis test and $\chi^{2}$ test, respectively. All p-values are exploratory.

\section{Results}

Comparison of immune cells in RCC patients compared to a healthy control group. In order to determine whether there exists a difference in the frequency and the phenotype of immune cell subpopulations between RCC patients and the age-matched control group, immunostaining of blood cells was performed with a large panel of mAbs. Despite the number of leukocytes was comparable between healthy donors and RCC patients, RCC patients exhibited a higher percentage of granulocytes and a lower percentage of lymphocytes as illustrated in Fig. 1A. The frequency of blood DC of RCC patients when compared to that of the control group was lower. Especially the $\mathrm{mDC} 1$ subpopulation of DC was depressed in patients, whereas no obvious difference could be found for $\mathrm{mDC} 2$ (data not shown) as well as pDC (Fig. 1B). Using $\mathrm{mAb}$ with a protein/fluorophore ratio of $1 / 1$, the monocytic expression 
Table II. Comparison of the preoperative values of RCC patients with age-matched healthy volunteers.

\begin{tabular}{|c|c|c|c|}
\hline Parameter & $\begin{array}{l}\text { Healthy } \\
\text { donors }\end{array}$ & $\begin{array}{c}\text { Patients } \\
<\text { pT3 }\end{array}$ & $\begin{array}{c}\text { Patients } \\
\geq \text { pT3 }\end{array}$ \\
\hline WBCs & $6.260 \pm 310$ & $6.500 \pm 402$ & $8.340 \pm 563$ \\
\hline Granulocytes & $4.227 \pm 310$ & $4.702 \pm 354$ & $6.139 \pm 385$ \\
\hline Monocytes & $351 \pm 39$ & $349 \pm 22$ & $441 \pm 42$ \\
\hline $\mathrm{CD} 16^{+} \mathrm{CD} 14 \mathrm{dim}$ & $25 \pm 3$ & $34 \pm 4$ & $33 \pm 6$ \\
\hline Monocyte DC & $19 \pm 2$ & $17 \pm 1$ & $13 \pm 2$ \\
\hline Lymphocytes & $1.670 \pm 111$ & $1.490 \pm 110$ & $1.760 \pm 237$ \\
\hline B cells & $197 \pm 21$ & $144 \pm 13$ & $169 \pm 41$ \\
\hline $\mathrm{T}$ cells & $1.251 \pm 90$ & $1.088 \pm 92$ & $1.292 \pm 181$ \\
\hline $\mathrm{CD} 8{ }^{+} \mathrm{T}$ cells & $434 \pm 50$ & $376 \pm 39$ & $364 \pm 59$ \\
\hline $\mathrm{CD} 4{ }^{+} \mathrm{T}$ cells & $817 \pm 68$ & $689 \pm 60$ & $928 \pm 139$ \\
\hline NK cells & $223 \pm 27$ & $237 \pm 29$ & $299 \pm 51$ \\
\hline $\mathrm{V} \alpha 24$ (NKT) & $8 \pm 2$ & $9 \pm 2$ & $11 \pm 4$ \\
\hline $\mathrm{CD} 28^{+} \mathrm{T}$ cells & $1.035 \pm 73$ & $872 \pm 72$ & $962 \pm 115$ \\
\hline $\mathrm{CD} 8{ }^{+} \mathrm{CD} 28^{+} \mathrm{T}$ & $273 \pm 26$ & $216 \pm 21$ & $196 \pm 24$ \\
\hline $\mathrm{ICOS}^{+} \mathrm{T}$ cells & $25 \pm 4$ & $27 \pm 6$ & $17 \pm 5$ \\
\hline $\mathrm{CD} 25^{+} \mathrm{T}$ cells & $389 \pm 42$ & $348 \pm 37$ & $439 \pm 68$ \\
\hline $\mathrm{CD} 4{ }^{+} \mathrm{CD} 25^{+} \mathrm{T}$ & $323 \pm 38$ & $314 \pm 40$ & $343 \pm 62$ \\
\hline $\mathrm{CD}^{4}{ }^{+} \mathrm{Foxp}^{+}{ }^{+} \mathrm{T}$ & $45 \pm 28$ & $45 \pm 39$ & $42 \pm 30$ \\
\hline $\mathrm{CD} 7^{+} \mathrm{T}$ cells & $215 \pm 41$ & $239 \pm 35$ & $320 \pm 83$ \\
\hline $\mathrm{PD} 1^{+} \mathrm{T}$ cells & $180 \pm 25$ & $186 \pm 25$ & $207 \pm 58$ \\
\hline CTLA4 ${ }^{+} \mathrm{T}$ cells & $16 \pm 7$ & $18 \pm 4$ & $20 \pm 9$ \\
\hline $\mathrm{CD}^{+}{ }^{+} \mathrm{CTLA}^{+}{ }^{+} \mathrm{T}$ & $3 \pm 1$ & $7 \pm 1$ & $5 \pm 2$ \\
\hline $\mathrm{CXCR}{ }^{+} \mathrm{T}$ cells & $538 \pm 48$ & $530 \pm 58$ & $620 \pm 138$ \\
\hline CD57+ NK cells & $115 \pm 15$ & $146 \pm 24$ & $209 \pm 39$ \\
\hline
\end{tabular}

Data are given as cells $/ \mu 1$.

of HLA-DR and APN/CD13 was quantified. Compared to healthy volunteers, monocytic HLA-DR expression was lower in RCC patients $(\mathrm{p}=0.089)$. Using a threshold of 5,000 ABC for a strongly diminished HLA-DR intensity on monocytes (HLA-DR ${ }^{\text {low }}$ ), the control group possessed $2.8 \pm 0.6 \%$ and RCC patients $7.5 \pm 1.2 \%$ of these HLA-DR ${ }^{\text {low }}$ monocytes $(\mathrm{p}=0.001)$, respectively.

In contrast, only minor differences could be found in the lymphocytic subpopulations of both groups. All the function-associated surface molecules investigated showed no significant differences with the exception of the numbers of $\mathrm{CD} 28^{+} \mathrm{CD}^{+} \mathrm{T}$ cells, which were lower in RCC patients than in the control group (Fig. 1C), whereas CTLA $4{ }^{+} \mathrm{CD} 8{ }^{+} \mathrm{T}$ cells were higher in RCC patients (Fig. 1D). In addition, a higher number of $\mathrm{CD}^{+} 7^{+} \mathrm{T}$ cells and $\mathrm{CD} 57^{+} \mathrm{NK}$ cells could be detected in RCC patients (Table II). No difference could be found for the number of FoxP $3^{+} \mathrm{CD}^{+}{ }^{+}$regulatory $\mathrm{T}$ cells in the blood of control group and tumor patients (Table II).
Tumor stage-dependent alterations of the immunophenotype. In order to determine whether there exists a tumor stage-dependent alteration in the frequency or phenotype of immune cell populations in peripheral blood, we compared the preoperative values of RCC patients with locally advanced $(\geq \mathrm{pT} 3)$ and early stage tumors $(<\mathrm{pT} 3)$ (Table II). The $\geq \mathrm{pT} 3$ group had higher WBC due to an increased number of granulocytes (Fig. 2A). The number of monocytes was also higher in the patient group $\geq \mathrm{pT} 3$, whereas DC counts were lower (Fig. 2B). Whereas patients with early tumor stages possessed $10.9 \mathrm{mDC} 1$ cells $/ \mu 1$ and $5.11 \mathrm{pDC}$ cells $/ \mu 1$, we estimated $7.84 \mathrm{mDC} 1$ cells $/ \mu 1$ and $4.51 \mathrm{pDC}$ cells $/ \mu 1$ in patients with $\geq p T 3$. WBC correlated with tumor stages $(p=0.031)$, but not with tumor grades (data not shown). In addition, the absolute numbers of DC correlated both with tumor grading of RCC lesions and with tumor staging (data not shown), whereas the frequency of DC (as percentage of leukocytes) correlated only with tumor staging $(\mathrm{p}=0.009)$.

The intensity of monocytic HLA-DR expression was diminished in the patient group $\geq \mathrm{pT} 3$ (Fig. 2C). This points to a decreased monocytic HLA-DR expression in advanced malignancy when compared to early tumor stages. Using the $5,000 \mathrm{ABC}$ threshold, we observed $5.4 \pm 1.1 \%$ of HLA-DR ${ }^{\text {low }}$ monocytes in patients with $<$ pT3 and $12.6 \pm 2.4 \%$ of HLA-DR ${ }^{\text {low }}$ monocytes in patients with $\geq \mathrm{pT} 3$. Furthermore, monocytic CD13 expression correlated with tumor staging exhibiting a higher intensity in advanced disease (Fig. 2C).

The number of $\mathrm{V} \alpha 24^{+}$NKT cells was only marginally higher in RCC patients with advanced tumor stages. In addition, the absolute counts for $\mathrm{T}$ cells $\left(\mathrm{CD}^{+}\right)$, B cells $\left(\mathrm{CD} 19^{+}\right)$and NK cells $\left(\mathrm{CD} 3{ }^{-}, \mathrm{CD}^{-} 6^{+}\right)$did not differ significantly between patients with early and advanced tumor stages (Table II). However, despite a high variability between individual patients there was a tendency to a higher amount of $\mathrm{CD}^{+} \mathrm{T}$ cells in advanced $\mathrm{RCC}$, whereas the number of $\mathrm{CD}^{+} \mathrm{T}$ cells remained similar in both groups. We found no significant difference in the absolute numbers of $\mathrm{CD} 25^{+} \mathrm{CD} 4{ }^{+}$ $\mathrm{T}$ cells between early and advanced tumor disease. Similarly, FoxP $3^{+} \mathrm{CD} 4^{+} \mathrm{T}$ cells did not differ between groups. Otherwise, tumor stages $\geq \mathrm{pT} 3$ had higher amounts of $\mathrm{CTLA}_{4}^{+}, \mathrm{PD}^{+}$and $\mathrm{CXCR}^{+} \mathrm{T}$ cells and reduced amounts of ICOS ${ }^{+} \mathrm{T}$ cells. In addition, a higher number of both $\mathrm{CD} 57^{+} \mathrm{T}$ cells and $\mathrm{CD} 57^{+}$ NK cells was detected in RCC stages $\geq$ pT3 (Fig. 2D).

Post-operative changes in immune cells between laparotomy and laparoscopy. Patients undergoing open tumor surgery spent on average $12.3 \pm 0.6$ days in hospital care, patients with laparoscopic tumor surgery $10 \pm 0.6$ days $(\mathrm{p}=0.016)$. This difference is caused by a higher percentage of advanced diseases in the laparotomy group, since patients with tumor stages pT1-2 were hospitalized a comparable time independent of the mode of surgery (data not shown). In order to investigate the immune competence and recovery of both patient groups, a set of immune cell parameters was measured before (p), one (d1), three (d3) and seven days (d7) after surgery. No significant differences between the pre-operative values within both groups of tumor surgery were found with the exception of the number of $\mathrm{CD} 57^{+} \mathrm{T}$ cells, which was higher in the open surgery group $(\mathrm{p}=0.047)$. One day after surgery (d1) the most obvious changes within the time course could be found. 

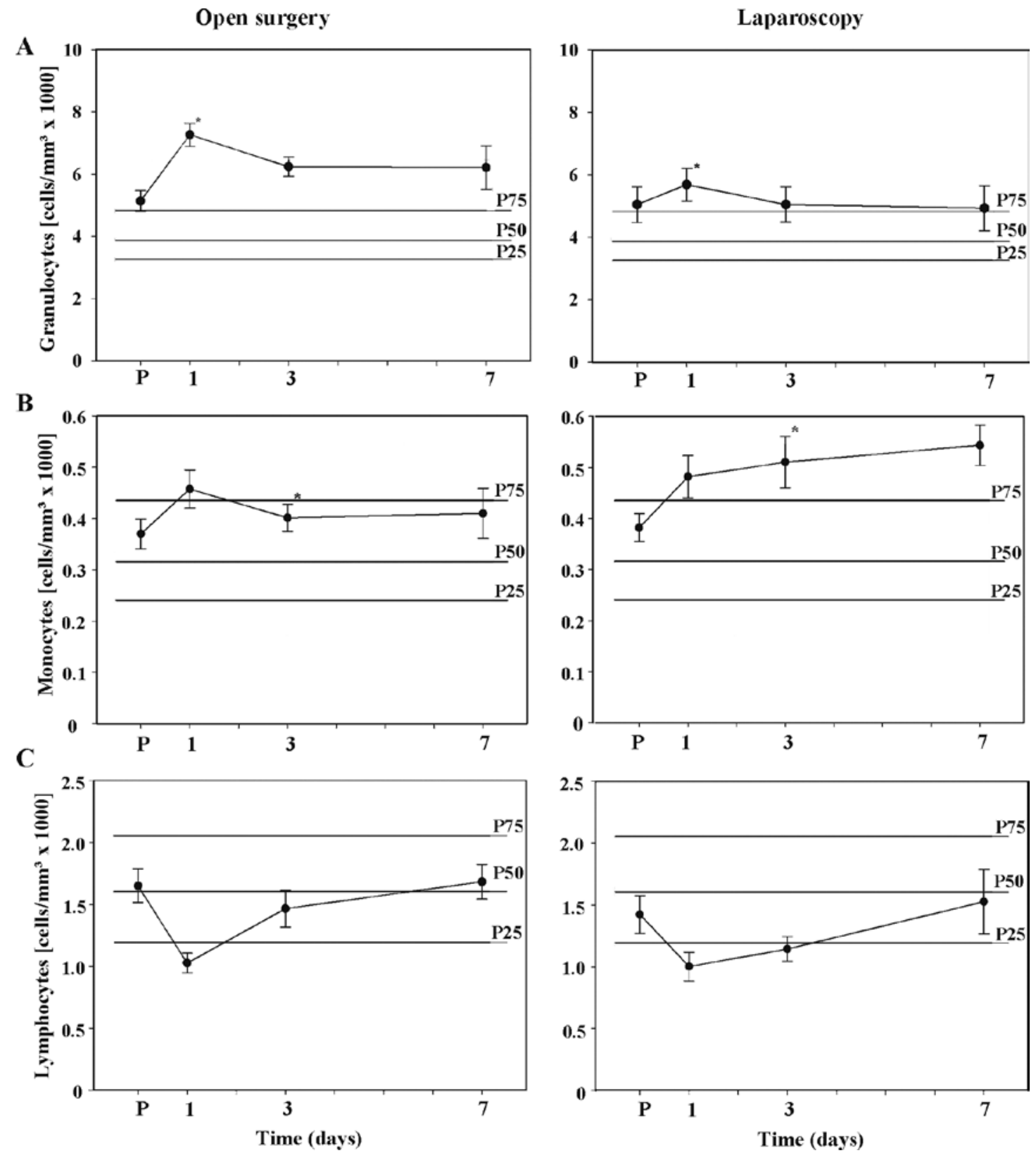

Figure 3. Comparison of the immune reconstitution of RCC patients upon open surgery and laparoscopy. The values of the control group are given as percentiles, with P25 (25th percentile), P50 and P75. The time course of the absolute numbers of granulocytes (A), monocytes (B), and lymphocytes (C) is shown with mean values \pm SEM. Significant differences between adjacent time points are marked by an asterisk.

During the post-operative follow-up, all markers investigated did at least partially recover, often with a faster normalization in the laparoscopic group of patients.

Most patients showed post-operatively elevated WBC counts caused in particular by a short-time increase of granulocytes (Fig. 3A), whereas the number of lymphocytes dropped (Fig. 3C). At time point d1, granulocytes rose to $142 \%$ of the preoperative value in case of the open surgery group and to $113 \%$ in the laparoscopy group. The absolute values of monocytes showed a slight increase at time point d1, with a further rise only in the laparoscopy group (significant difference at d3, Fig. 3B). Otherwise lymphocytes decreased to $62 \%$ of the preoperative value in case of the open surgery group and to $70 \%$ in the laparoscopy group. At time point d1, the number of T-, B- and NK cells declined to $50-80 \%$ of the preoperative value (Table III). Furthermore, most of the T cells with special function-associated surface molecules studied showed a decline at the first postoperative day (Table III). In addition, blood DC declined after surgery and did not recover until 7 days in the laparotomy group with a significant difference at day 7.

Time kinetics revealed an immune depression of all RCC patients post-surgery documented by a decreased monocytic HLA-DR intensity (Fig. 4A). At the first day after surgery, the percentage of HLA-DR ${ }^{\text {low }}$ monocytes increased from 7 up to $30 \%$ of monocytes in the open surgery group and to $19 \%$ of monocytes in the laparoscopy patients (Fig. 4B). The expression of monocytic HLA-DR expression slowly recovered over time, reaching pre-operative values only in the laparoscopic group within 7 days. Monocytic APN/CD13 
Table III. Time course of selected immune parameters in RCC patients undergoing open surgery or laparoscopy.

\begin{tabular}{|c|c|c|c|c|c|}
\hline Parameter & Surgery & d0 & $\mathrm{d} 1(\%$ of $\mathrm{d} 0)$ & $\mathrm{d} 3(\%$ of $\mathrm{d} 0)$ & $\mathrm{d} 7(\%$ of $\mathrm{d} 0)$ \\
\hline \multirow[t]{2}{*}{ WBCs } & Open surgery & $7.244 \pm 426$ & 124 & 116 & 114 \\
\hline & Laparoscopy & $6.620 \pm 610$ & 108 & 103 & 111 \\
\hline \multirow[t]{2}{*}{ Granulocytes } & Open surgery & $5.130 \pm 330$ & 142 & 122 & 121 \\
\hline & Laparoscopy & $5.050 \pm 570$ & 113 & 100 & 98 \\
\hline \multirow[t]{2}{*}{ Monocytes } & Open surgery & $370 \pm 29$ & 124 & 108 & 111 \\
\hline & Laparoscopy & $382 \pm 28$ & 126 & 134 & 142 \\
\hline \multicolumn{6}{|l|}{ CD16+CD14dim } \\
\hline \multirow[t]{2}{*}{ monocytes } & Open surgery & $34 \pm 4$ & 79 & 88 & 85 \\
\hline & Laparoscopy & $33 \pm 6$ & 97 & 124 & 136 \\
\hline \multirow[t]{2}{*}{ DC } & Open surgery & $16 \pm 1$ & 94 & 87.5 & 81 \\
\hline & Laparoscopy & $15 \pm 2$ & 73 & 113 & 133 \\
\hline \multirow[t]{2}{*}{ Lymphocytes } & Open surgery & $1.650 \pm 136$ & 62 & 89 & 102 \\
\hline & Laparoscopy & $1.423 \pm 154$ & 70 & 80 & 107 \\
\hline \multirow[t]{2}{*}{ B cells } & Open surgery & $155 \pm 20$ & 78 & 92 & 139 \\
\hline & Laparoscopy & $146 \pm 22$ & 82 & 94 & 120 \\
\hline \multirow[t]{2}{*}{ T cells } & Open surgery & $1.211 \pm 110$ & 61.5 & 86 & 101 \\
\hline & Laparoscopy & $1.034 \pm 126$ & 71 & 80 & 103 \\
\hline \multirow[t]{2}{*}{$\mathrm{CD}^{+} \mathrm{T}$ cells } & Open surgery & $387 \pm 44$ & 66 & 91 & 89 \\
\hline & Laparoscopy & $350 \pm 46$ & 75 & 83 & 97 \\
\hline \multirow[t]{2}{*}{$\mathrm{CD}^{+}{ }^{+} \mathrm{T}$ cells } & Open surgery & $799 \pm 77$ & 61 & 87 & 105 \\
\hline & Laparoscopy & $683 \pm 93$ & 69 & 79 & 107 \\
\hline \multirow[t]{2}{*}{ NK cells } & Open surgery & $261 \pm 35$ & 52 & 77 & 79 \\
\hline & Laparoscopy & $243 \pm 35$ & 61 & 72 & 92 \\
\hline \multirow[t]{2}{*}{$\mathrm{V} \alpha 24(\mathrm{NKT})$} & Open surgery & $10 \pm 2$ & 50 & 70 & 90 \\
\hline & Laparoscopy & $7 \pm 2$ & 71 & 86 & 100 \\
\hline \multirow[t]{2}{*}{ CD28+ T cells } & Open surgery & $931 \pm 73$ & 63 & 90 & 109 \\
\hline & Laparoscopy & $839 \pm 109$ & 76 & 81 & 99 \\
\hline \multirow[t]{2}{*}{$\mathrm{CD} 8{ }^{+} \mathrm{CD} 28^{+} \mathrm{T}$} & Open surgery & $210 \pm 19$ & 69 & 99.5 & 102 \\
\hline & Laparoscopy & $210 \pm 32$ & 78 & 85 & 74 \\
\hline \multirow[t]{2}{*}{$\mathrm{ICOS}^{+} \mathrm{T}$ cells } & Open surgery & $25 \pm 6$ & 64 & 80 & 92 \\
\hline & Laparoscopy & $23 \pm 8$ & 52 & 52 & 61 \\
\hline \multirow[t]{2}{*}{$\mathrm{CD} 25^{+} \mathrm{T}$ cells } & Open surgery & $384 \pm 40$ & 63 & 94.5 & 117 \\
\hline & Laparoscopy & $355 \pm 59$ & 61 & 73.5 & 100 \\
\hline \multirow[t]{2}{*}{$\mathrm{CD}^{+}{ }^{+} \mathrm{CD} 25^{+} \mathrm{T}$} & Open surgery & $324 \pm 39$ & 61 & 92 & 118 \\
\hline & Laparoscopy & $318 \pm 63$ & 58 & 69.5 & 85.5 \\
\hline \multirow[t]{2}{*}{$\mathrm{CD} 7^{+} \mathrm{T}$ cells } & Open surgery & $306 \pm 50$ & 55 & 75.5 & 79 \\
\hline & Laparoscopy & $187 \pm 30$ & 69.5 & 78 & 104 \\
\hline \multirow[t]{2}{*}{ PD1 ${ }^{+} \mathrm{T}$ cells } & Open surgery & $217 \pm 32$ & 60 & 90 & 85 \\
\hline & Laparoscopy & $150 \pm 35$ & 65 & 77 & 76 \\
\hline \multirow[t]{2}{*}{$\mathrm{CTLA}^{+}{ }^{+} \mathrm{T}$ cells } & Open surgery & $21 \pm 5$ & 52 & 109.5 & 119 \\
\hline & Laparoscopy & $15 \pm 6$ & 140 & 93 & 120 \\
\hline \multirow[t]{2}{*}{$\mathrm{CD}^{+}{ }^{+\mathrm{CTLA}_{4}+\mathrm{T}}$} & Open surgery & $6 \pm 1$ & 67 & 150 & 117 \\
\hline & Laparoscopy & $6 \pm 2$ & 117 & 83 & 67 \\
\hline $\mathrm{CXCR}^{+} \mathrm{T}$ cells & Open surgery & $613 \pm 74$ & 62 & 88 & 95 \\
\hline & Laparoscopy & $458 \pm 81$ & 72 & 75 & 109 \\
\hline $\mathrm{CD} 57^{+} \mathrm{NK}$ & Open surgery & $168 \pm 27$ & 51 & 79 & 79 \\
\hline & Laparoscopy & $159 \pm 33$ & 58 & 62 & 61 \\
\hline
\end{tabular}

The frequency of different immune cell subpopulations and respective functional immune parameters were determined by flow cytometry before operation (d0), at the first (d1), third (d3) and day $7(\mathrm{~d} 7)$ after surgery. Data are given as cells/ $\mu 1(\mathrm{~d} 0)$ and as relative values (percentage of $\mathrm{d} 0$ ). 

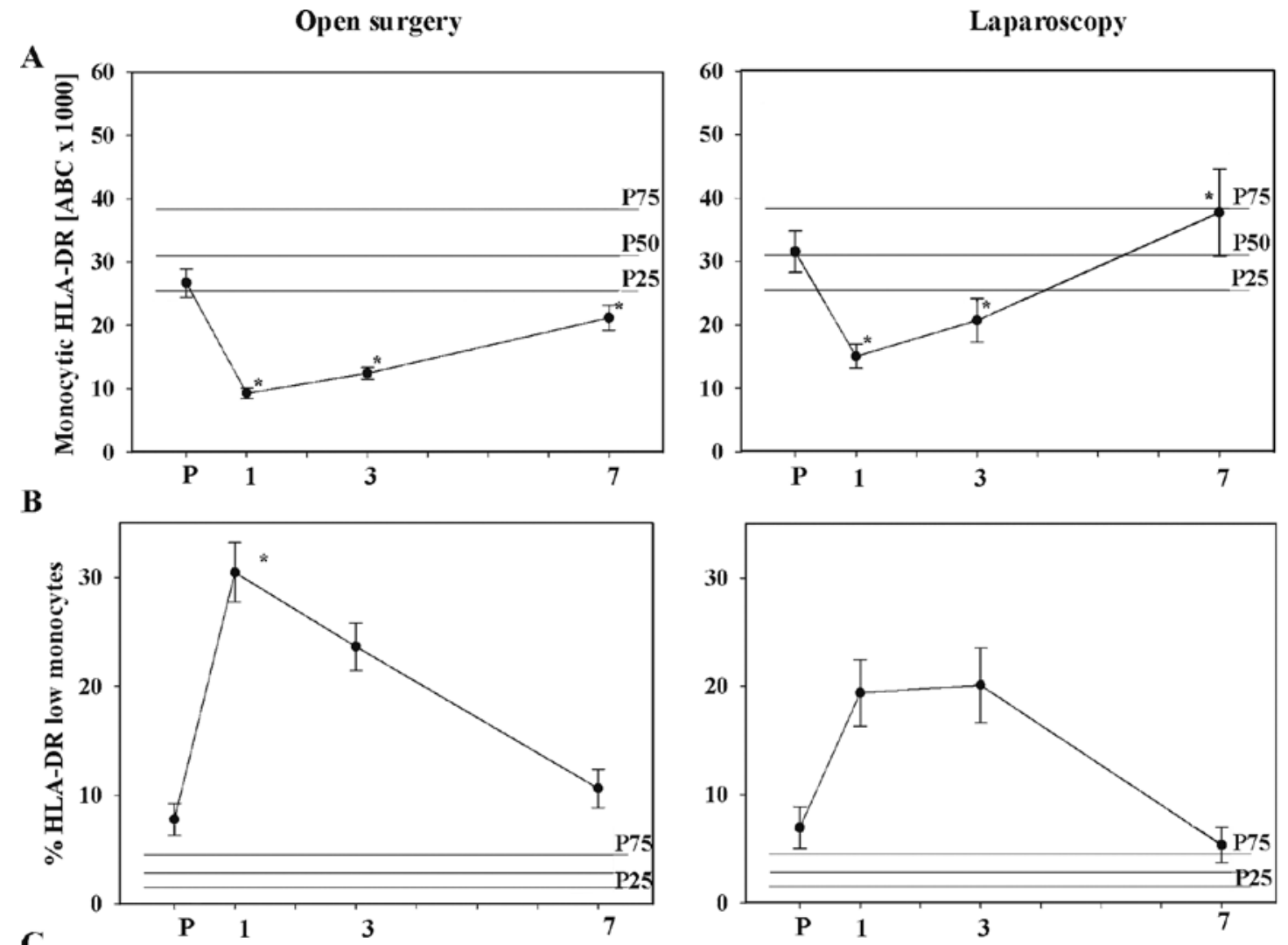

C
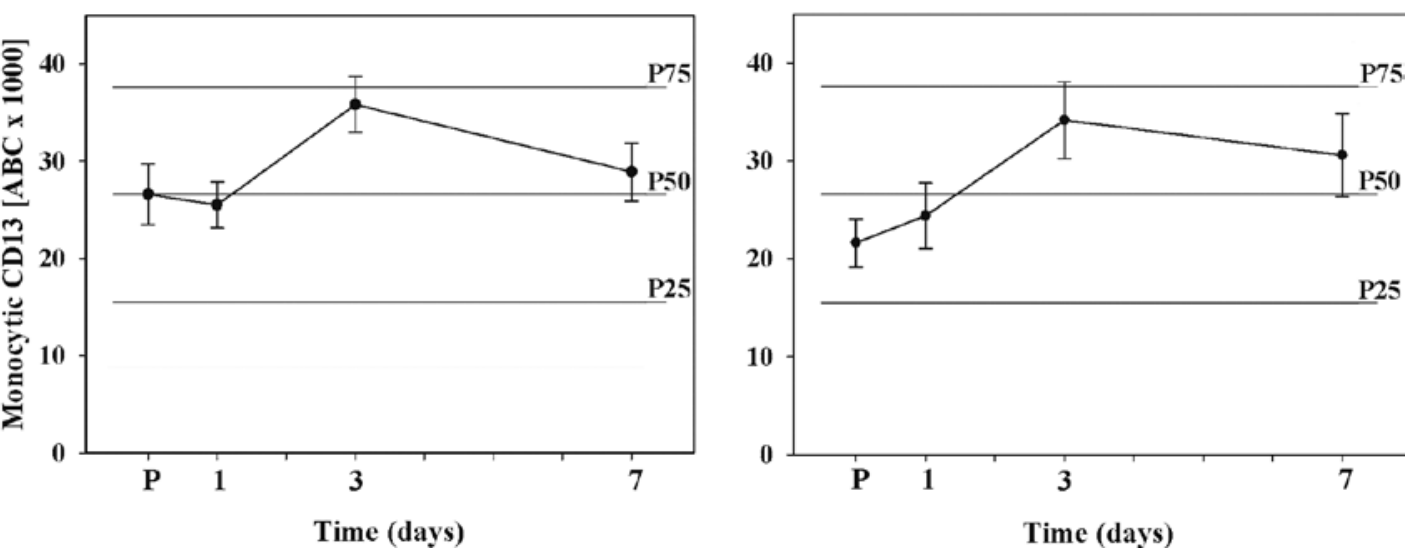

Figure 4. Comparison of the immune reconstitution of RCC patients upon open surgery and laparoscopy. The values of the control group are given as percentiles, with P25 (25th percentile), P50 and P75. The time course of the monocytic HLA-DR intensity is illustrated in (A), the number of HLA-DR low monocytes in (B), and the monocytic CD13 intensity in (C).

expression increased on monocytes in both patient groups with a maximum at day 3 after surgery (Fig. 4C).

\section{Discussion}

Using multi-color flow cytometry, we searched for surrogate markers to monitor the immune cell repertoire and function in RCC patients before and after tumor surgery. An RCC-induced immune dysfunction in patients at first diagnosis has been described by Porta and co-authors (11) demonstrating a marked suppression of both CD4/CD45RA naive and CD4/CD45RO memory T cells, CD16 ${ }^{+} \mathrm{NK}$ cells, and total circulating DC despite a significant activation of HLA-DR ${ }^{+} \mathrm{T}$ lymphocytes and of the CD56 ${ }^{+} \mathrm{NK}$ cell subset. In addition, distinct peri-operative immunodysfunctions have been demonstrated in RCC patients, such as increased leukocyte and granulocyte counts, but low $\mathrm{T}$ cell counts until post-operative day 3 (12). These results were extended by our study investigating differences: i) in immune cells between RCC patients and age-matched healthy volunteers; ii) between preoperative values of patients with early $(<\mathrm{pT} 3)$ and locally advanced tumor stages ( $\geq$ pT3); and iii) in the post-operative time course between laparoscopic and open surgery. We extended immune parameters on subpopulations of blood $\mathrm{DC}$, several function-related markers of $\mathrm{T}$ cells and on the quantification of monocytic intensity of HLA-DR and APN/ CD13. Differences in cell numbers and functional surface marker expression were mainly observed in cells of the innate immune system, such as granulocytes, monocytes and DC, but rarely in T cells. 
For the first time, we here characterised immune cell markers associated with advanced tumor stages in RCC patients. Tumor staging represents the most useful and clinically available predictor of RCC patients' outcome. Comparing early stage RCC $(<\mathrm{pT} 3)$ to the locally advanced disease ( $\geq \mathrm{pT} 3$ ), a higher WBC was detected in advanced tumor stages due to higher numbers of granulocytes. This is in line with multivariate analysis identifying a high blood neutrophil count (>6.0 x 10E9/1) as independent poor prognostic factor in patients with metastatic RCC receiving IL-2 (4). Furthermore, granulocytes might represent an adverse prognostic factor in patients with metastatic RCC treated with anti-VEGF agents (13). The role of granulocytes in advanced tumor disease has not yet been elucidated in detail. However, tumors are known to both drive myelopoiesis, sometimes leading to a clinically apparent leukocytosis, and to inhibit the differentiation of myeloid cells, resulting in a qualitative change in myelopoiesis (reviewed in ref. 14). Recent data revealed arginase-producing MDSC in RCC as a granulocytic subpopulation $(15,16)$. Abrogation of the MDCS-mediated immune suppression results in the restoration of cytokine production and proliferation of $\mathrm{T}$ cells (15). In addition, granulocytes can be present as tumor-associated immune cells with an ambiguous role. Tumor-infiltrating neutrophils deliver a potent proangiogenic moiety, i.e., the unencumbered inhibitor-free metalloprotease (MMP)-9 (17).

Our results demonstrate the suitability of blood DC number as marker of immune suppression, exhibiting lower counts in RCC patients compared to a healthy control group. The implementation of a commercially available test kit for whole blood analysis without any separation step for the cell labeling resulted in a lower blood DC count $(0.24 \%$ of leukocytes) when compared to other authors using density gradient separation of mononuclear cells $(\geq 0.6 \%$ of leukocytes) (18). The blood DC were in particular low in patients with advanced tumor disease ( $\geq \mathrm{pT} 3$ ): DC correlated both with tumor staging and grading. Human blood contains different subgroups of DC precursors, among them conventional $\mathrm{CD}_{11 \mathrm{c}^{+}} \mathrm{mDC}$ and $\mathrm{pDC}$ as the major producers of type I interferon (19). Although CD141 ${ }^{+}$mDC2 have been demonstrated as the main human DC subset involved in stimulating CTL responses (20), differences of blood DC observed in this study concerned the number of total DC as well as CD1c ${ }^{+}$ mDC1, but rarely the mDC2 subset, which was lower than one tenth of the number of $\mathrm{mDC} 1$. It is noteworthy that the $\mathrm{mDC} 1$ frequency could predict progression-free survival in advanced RCC patients treated with sunitinib (18).

Patients with temporary immunodeficiency are characterized by a diminished expression of the major histocompatibility complex (MHC) class II antigens on monocytes, which play a critical role in the induction of the cellular immune response (21). Attenuation of HLA-DR on the surface of circulating monocytes is generally accepted as a reliable marker for an immune dysfunction and has been described in several patients, e.g. after multiple trauma, burn injury, or major surgery. The mechanisms involved in the regulation of HLA-DR include internalization of the HLA-DR $\beta$-chain after ubiquination via members of the MARCH ubiquitin ligase family (22). Interestingly, MDSC can be defined as cells positive for CD14 with low or negative HLA-DR expression, and
$0.9 \%$ of leukocytes of RCC patients exhibit such a phenotype (18). For the first time, we measure the number of HLA-DR ${ }^{\text {low }}$ monocytes in RCC patients on an antibodies-bound-per-cell level, which allowed to accurately quantify the absolute antigen expression level, taking variations in instrument performance into account. Fluorescence intensity calibration allows the establishment of a comparable window of analysis across different times and laboratories. Mean values of an HLA-DR expression $<5,000$ ABC for the whole monocytic population have been designated as 'immunoparalysis' in former studies (21), since the patients are at high risk of infectious diseases. Despite the threshold of 5,000 ABC HLA-DR, used by us for identifying HLA-DR ${ }^{\text {low }}$ monocytes, is an artificial one, we could show a difference between healthy controls and tumor patients as well as between patients with early and late RCC stages. This threshold value might be used for the investigation of patients with other tumor entities or for the monitoring of tumor therapies. The most obvious increase in the number of HLA-DR ${ }^{\text {low }}$ monocytes was found at the first day after tumor surgery and was significantly higher in patients with open tumor surgery.

In an earlier study of polytrauma patients the observed decrease in monocytic HLA-DR expression was accompanied by a delayed strong increase of membrane peptidase APN/ CD13 expression (23). In the present study, we describe for the first time that the decrease in monocytic HLA-DR intensity is paralleled by an increase in APN/CD13 intensity in advanced RCC tumor stages. Analogous to polytrauma patients after surgery, the decrease of monocytic HLA-DR expression after RCC surgery was accompanied by a time-delayed increase of APN/CD13 intensity. However, the molecular mechanisms resulting in the higher monocytic APN/CD13 expression after surgery or in advanced tumor stages remain to be elucidated. In addition to monocytic differentiation, lipopolysaccharide as ligand of a pattern recognition receptor (23) as well as the cytokines IL-4 (24) and TGF- $\beta$ (25) can up-regulate monocytic APN/CD13 expression in vitro. Since elevated TGF- $\beta$ concentrations have been detected in the sera of RCC patients (26) and since TGF- $\beta$ is able to suppress HLA-DR expression (27), this immunosuppressive cytokine might be involved in the observed effect. The functional consequences of a higher monocytic APN/CD13 intensity in patients with RCC stages of $\geq$ pT 3 remain elusive as well. The ubiquitously expressed ectopeptidase is involved in multiple cellular functions and has been proposed to play a role in the modulation of kinins, neuropeptides and chemotactic mediators as well as in adhesion, cell-cell interactions and signal transduction (reviewed in ref. 28).

In this study, the frequency of lymphocytes was significantly lower in RCC patients, which was paralleled by a higher percentage of granulocytes. Though the preoperative absolute counts of $\mathrm{T}$ cells (both $\mathrm{CD}^{+}$and $\mathrm{CD} 8^{+}$cells) and $\mathrm{B}$ cells were often lower in RCC patients compared to healthy age-matched controls, this difference was not significant. A decreased function of circulating $\mathrm{T}$ cells has been described in many human malignancies (29). In vitro data indicate that the same functional impairments seen in tumor infiltrating lymphocytes are found in both circulating and lymph node lymphocytes of patients with cancer. Thus, human tumors exert profound suppressive effects on both local and systemic 
antitumor immunity (30). Functionally distinct $\mathrm{T}$ cell populations can be defined by the expression of specific cell surface antigens, e.g. the chemokine receptors CXCR3 and CCR5 have been discussed to be exclusively expressed on Th1 lymphocytes (31). In this study, a higher number of CXCR3 ${ }^{+}$ $\mathrm{T}$ cells was found in advanced RCC stages. In addition, the surface receptor CD57 expressed on both T and NK cells has been associated with a history of numerous cell divisions, short telomeres and replicative senescence (32). A high frequency of $\mathrm{CD} 57^{+}$cytotoxic $\mathrm{T}$ cells in the blood of RCC patients has been found in earlier studies and has been discussed to represent a predictive marker for the survival of RCC patients (33). Concerning CD57 expression of T and NK cells a tendency to a higher number of $\mathrm{CD} 57^{+}$cells in RCC patients compared to the control group as well as an increased CD57 expression in patients with advanced tumor stages compared to early stages was found: $51 \%$ of NK cells expressed CD57 in the age-matched control group, $62 \%$ of NK cells at the early and $70 \%$ at the late RCC stages. The high standard error of the mean for the number of the $\mathrm{CD} 57^{+}$ $\mathrm{T}$ cells in patients with advanced tumor stages implies that there might exist different patient subgroups, which vary with respect to their outcome. A higher number of patients would be needed to clarify this point.

The molecular basis for the cell-intrinsic control of $\mathrm{T}$ cell activation and tolerance resides within groups of activating and inhibitory receptors. The molecules CTLA4/CD152 as well as PD1/CD279 represent negative regulators of T cells involved in peripheral tolerance and a higher number of $\mathrm{T}$ cells positive for these molecules was found by us especially in the advanced tumor stages. CTLA4 signaling via the costimulatory molecules CD80 and CD86 on antigen-presenting cells provides a negative feedback loop to activated $\mathrm{T}$ cells thereby dampening their activity (34). Similarly, PD1 signals inhibit T-cell activation and proliferation and PD1 expression parallels $\mathrm{T}$ cell exhaustion in chronic viral infection (35). Increased numbers of tumor-infiltrating immune cells expressing PD-1 were found in patients with high-risk RCC tumors (36). In contrast, the inducible costimulator (ICOS) representing a stimulatory receptor on T cells (37) exhibits the smallest values in patients with advanced tumor stages. The circulating $\mathrm{CD} 8{ }^{+} \mathrm{CD} 28$ - effector subpopulation might have a significant greater propensity to undergo spontaneous apoptosis in patients with cancer (30). Indeed, higher amounts of $\mathrm{CD} 8^{+} \mathrm{CD} 28^{-} \mathrm{T}$ cells were found in RCC patients compared to the control, whereas the difference between early and late tumor stages was less pronounced. We observed no difference in the amounts of FoxP3 ${ }^{+}$regulatory $\mathrm{T}$ cells between tumor patients and the control group. This is in contrast to results of Griffiths et al (38) who reported a significant difference between renal cancer patients $\left(2.5 \%\right.$ FoxP $^{+} \mathrm{T}$ cells) and the control group $(1.5 \%)$. We estimated values of $4-6 \%$ FoxP3 $^{+}$ $\mathrm{T}$ cells associated with a high standard error. We are sure that the permeabilization process has a significant effect on our values and would prefer surface staining (such as $\mathrm{CD} 127 \mathrm{dimCD} 25^{++} \mathrm{CD} 4+$ ) in future studies.

Taken together, our study describes for the first time putative biomarkers, which might serve as useful tools for monitoring of immune cell functions in RCC patients pre- and post-surgery. Combining immunophenotyping with functional tests would be useful for a better estimation of the immune competence of patients. Furthermore, larger randomised trials determining the immune phenotype and the correlation of these markers with clinical data, in particular with the survival rate, will be required.

\section{References}

1. Saylor PJ and Michaelson MD: New treatments for renal cell carcinoma: targeted therapies. J Natl Compr Cancer Netw 7: 645-656, 2009.

2. Facchini G, Perri F, Caraglia M, et al: New treatment approaches in renal cell carcinoma. Anticancer Drugs 20: 893-900, 2009.

3. Downs TM, Schultzel M, Shi H, Sanders C, Tahir Z and Sadler GR: Renal cell carcinoma: risk assessment and prognostic factors for newly diagnosed patients. Crit Rev Oncol Hematol 70: 59-70, 2009.

4. Donskov F and von der Maase $\mathrm{H}$ : Impact of immune parameters on long-term survival in metastatic renal cell carcinoma. J Clin Oncol 24: 1997-2005, 2006.

5. Cesana GC, DeRaffele G, Cohen S, et al: Characterization of $\mathrm{CD} 4{ }^{+} \mathrm{CD} 25^{+}$regulatory $\mathrm{T}$ cells in patients treated with high-dose interleukin-2 for metastatic melanoma or renal cell carcinoma. J Clin Oncol 24: 1169-1177, 2006.

6. Griffiths RW, Elkord E, Gilham DE, Ramani V, Clarke N, Stern PL and Hawkins RE: Frequency of regulatory T cells in renal cell carcinoma patients and investigation of correlation with survival. Cancer Immunol Immunother 56: 1743-1753, 2007.

7. Kusmartsev S, Su Z, Heiser A, et al: Reversal of myeloid cellmediated immunosuppression in patients with metastatic renal cell carcinoma. Clin Cancer Res 14: 8270-8278, 2008.

8. Ni Choileain N and Redmond HP: Cell response to surgery. Arch Surg 141: 1132-1140, 2006.

9. Ljungberg B, Cowan NC, Hanbury DC, et al: EAU guidelines on renal cell carcinoma: the 2010 update. Eur Urol 58: 398-406, 2010.

10. Nicholson ML, Kaushik M, Lewis GR, et al: Randomized clinical trial of laparoscopic versus open donor nephrectomy. Br J Surg 97: 21-28, 2010.

11. Porta C, Bonomi L, Lillaz B, et al: Renal cell carcinomainduced immunosuppression: an immunophenotypic study of lymphocyte subpopulations and circulating dendritic cells. Anticancer Res 27: 165-173, 2007.

12. Böhm M, Ittenson A, Philipp C, Röhl FW, Ansorge S and Allhoff EP: Complex peri-operative immuno-dysfunction in patients with renal cell carcinoma. J Urol 66: 831-836, 2001.

13. Choueiri TK, Garcia JA, Elson P, et al: Clinical factors associated with outcome in patients with metastatic clear-cell renal cell carcinoma treated with vascular endothelial growth factortargeted therapy. Cancer 110: 543-550, 2007.

14. Wilcox RA: Cancer-associated myeloproliferation: old association, new therapeutic target. Mayo Clin Proc 85: 656-663, 2010.

15. Ochoa AC, Zea AH, Hernandez C and Rodriguez PC: Arginase, prostaglandins, and myeloid-derived suppressor cells in renal cell carcinoma. Clin Cancer Res 13: S721-S726, 2007.

16. Rodriguez PC, Ernstoff MS, Hernandez C, Atkins M, Zabaleta J, Sierra R and Ochoa AC: Arginase I-producing myeloid-derived suppressor cells in renal cell carcinoma are a subpopulation of activated granulocytes. Cancer Res 69: 1553-1560, 2009.

17. Ardi VC, Kupriyanova TA, Deryugina EI and Quigley JP: Human neutrophils uniquely release TIMP-free MMP-9 to provide a potent catalytic stimulator of angiogenesis. Proc Natl Acad Sci USA 104: 20262-20267, 2007.

18. van Cruijsen H, van der Veldt AA, Vroling L, et al: Sunitinibinduced myeloid lineage redistribution in renal cell cancer patients: $\mathrm{CD} 1 \mathrm{c}^{+}$dendritic cell frequency predicts progressionfree survival. Clin Cancer Res 14: 5884-5892, 2008.

19. Dzionek A, Fuchs A, Schmidt P, et al: BDCA-2, BDCA-3, and BDCA-4: three markers for distinct subsets of dendritic cells in human peripheral blood. J Immunol 165: 6037-6046, 2000.

20. Jongbloed SL, Kassianos AJ, McDonald KJ, et al: Human CD141 ${ }^{+}\left(\right.$BDCA-3) ${ }^{+}$dendritic cells (DCs) represent a unique myeloid DC subset that cross-presents necrotic cell antigens. J Exp Med 207: 1247-1260, 2010. 
21. Döcke WD, Höflich C, Davis KA, et al: Monitoring temporary immunodepression by flow cytometric measurement of monocytic HLA-DR expression: a multicenter standardized study. Clin Chem 51: 2341-2347, 2005.

22. Thibodeau J, Bourgeois-Daigneault MC, Huppe G, et al: Interleukin-10-induced MARCH1 mediates intracellular sequestration of MHC class II in monocytes. Eur J Immunol 38: 1225-1230, 2008.

23. Huschak G, Zur Nieden K, Stuttmann R and Riemann D: Changes in monocytic expression of aminopeptidase N/CD13 after major trauma. Clin Exp Immunol 134: 491-496, 2003.

24. van Hal PT, Hopstaken-Broos JP, Prins A, et al: Potential indirect anti-inflammatory effects of IL-4. Stimulation of human monocytes, macrophages, and endothelial cells by IL-4 increases aminopeptidase-N activity (CD13; EC 3.4.11.2). J Immunol 153: 2718-2728, 1994.

25. Kehlen A, Geisler M, Olsen J, Sablotzki A, Langner J and Riemann D: IL-10 and TGF-beta differ in their regulation of aminopeptidase N/CD13 expression in monocytes. Int J Mol Med 13: 877-882, 2004.

26. Junker U, Haufe CC, Nuske K, et al: Elevated plasma TGF-beta1 in renal diseases: cause or consequence? Cytokine 12: 1084-1091, 2000.

27. Navarrete Santos A, Kehlen A, Schütte W, Langner J and Riemann D: Regulation by transforming growth factor-betal of class II mRNA and protein expression in fibroblast-like synoviocytes from patients with rheumatoid arthritis. Int Immunol 10: 601-607, 1998

28. Riemann D, Kehlen A and Langner J: CD13 - not just a marker in leukemia typing. Immunol Today 20: 83-88, 1999.

29. Whiteside TL: Immune suppression in cancer: effects on immune cells, mechanisms and future therapeutic interventions. Semin Cancer Biol 16: 3-15, 2006.

30. Whiteside TL: Immune responses to malignancies. J Allergy Clin Immunol 125 (2 Suppl. 2): S272-S283, 2010.
31. Qin S, Rottman JB, Myers P, et al: The chemokine receptors CXCR3 and CCR5 mark subsets of T cells associated with certain inflammatory reactions. J Clin Invest 101: 746-754, 1998.

32. Tarazona R, DelaRosa O, Alonso C, et al: Increased expression of NK cell markers on T lymphocytes in aging and chronic activation of the immune system reflects the accumulation of effector/senescent T cells. Mech Ageing Dev 121: 77-88, 2000.

33. Characiejus D, Pasukoniene V, Kazlauskaite N, Valuckas KP, Petraitis T, Mauricas M and Den Otter W: Predictive value of CD8highCD57+ lymphocyte subset in interferon therapy of patients with renal cell carcinoma. Anticancer Res 22: 3679-3683, 2002.

34. Greenwald RJ, Freeman GJ and Sharpe AH: The B7 family revisited. Annu Rev Immunol 23: 515-548, 2005.

35. Sharpe AH, Wherry EJ, Ahmed R and Freeman GJ: The function of programmed cell death 1 and its ligands in regulating autoimmunity and infection. Nat Immunol 8: 239-245, 2007.

36. Thompson RH, Dong H, Lohse CM, Leibovich BC, Blute ML, Cheville JC and Kwon ED: PD-1 is expressed by tumor-infiltrating immune cells and is associated with poor outcome for patients with renal cell carcinoma. Clin Cancer Res 13: 1757-1761, 2007.

37. Dong C, Juedes AE, Temann UA, Shresta S, Allison JP Ruddle NH and Flavell RA: ICOS co-stimulatory receptor is essential for T-cell activation and function. Nature 409: 97-101, 2001.

38. Griffiths RW, Elkord E, Gilham DE, Ramani V, Clarke N, Stern PL and Hawkins RE: Frequency of regulatory T cells in renal cell carcinoma patients and investigation of correlation with survival. Cancer Immunol Immunother 56: 1743-1753, 2007. 